\title{
Gestão de águas para habitações localizadas em zonas rurais: estudo de caso
}

\author{
Water management for housing located in rural areas: case study \\ Gestión del agua para viviendas ubicadas en zonas rurales: estudio de caso
}

Recebido: 06/01/2022 | Revisado: 11/01/2022 | Aceito: 26/01/2022 | Publicado: 28/01/2022

\author{
Eliezio Nascimento Barboza \\ ORCID: https://orcid.org/0000-0001-8100-9389 \\ Instituto Federal do Ceará, Brasil \\ E-mail: eliezio1999@outlook.com \\ Valdemir Fonseca da Silva \\ ORCID: https://orcid.org/0000-0001-7871-5434 \\ Universidade Federal da Fronteira Sul, Brasil \\ E-mail: valsilverstone@hotmail.com \\ Agílio Tomaz Marques \\ ORCID: https://orcid.org/0000-0001-8364-5063 \\ Universidade Federal de Campina Grande, Brasil \\ E-mail: agiliotomaz@hotmail.com \\ Suzana Araújo dos Santos \\ ORCID: https://orcid.org/0000-0001-5955-9421 \\ Universidade Federal de Campina Grande, Brasil \\ E-mail: suzana.santos2007@yahoo.com.br \\ Adryele Gomes Maia \\ ORCID: https://orcid.org/0000-0002-7433-7138 \\ Universidade Federal do Rio Grande do Norte, Brasil \\ E-mail: adryelegm@gmail.com \\ Francisco Igor Dalles da Mata Vieira \\ ORCID: https://orcid.org/0000-0002-9219-9090 \\ Instituto Federal do Ceará, Brasil \\ E-mail: igordm@gmail.com \\ Rubenia de Oliveira Costa \\ ORCID: https://orcid.org/0000-0003-2559-2885 \\ Universidade Federal de Campina Grande, Brasil \\ E-mail: rubeniaadm@gmail.com \\ Patrício Borges Maracajá \\ ORCID: https://orcid.org/0000-0003-4812-0389 \\ Universidade Federal de Campina Grande, Brasil \\ E-mail: patriciomaracaja@gmail.com
}

\begin{abstract}
Resumo
A sustentabilidade vem sendo cada vez mais discutida por se tratar de uma necessidade. Adotarmos medidas sustentáveis é uma maneira que devemos ter para proteger o meio ambiente. São muitas as maneiras que podemos implementar no nosso dia a dia para amenizar os impactos gerados, dentre elas podemos fazer o gerenciamento adequado dos resíduos, reaproveitar e reciclar o máximo possível, implementar sistemas de reaproveitamento de água da chuva e utilizar energia solar. Adotando medidas como essas dos âmbitos econômicos, social e ambiental podemos dizer que estamos exercendo a sustentabilidade. Nesse contexto, o presente trabalho tem como objetivo a elaboração de um roteiro para gestão das águas para casas populares elaborando ações que levem a diminuição do desperdício de águas e melhor reaproveitamento delas. Para tanto, foi realizado um estudo de caso numa residência unifamiliar de $216 \mathrm{~m}^{2}$ evidenciando os resultados de cada etapa. A partir do resultado, pode-se concluir que sistemas de reuso de água cinza e aproveitamento de água de chuva são claros e reais, contribuem para a conservação da água, pois diminuem o consumo de água potável para fins menos nobres e contribuem para a sustentabilidade hídrica das cidades.
\end{abstract}

Palavras-chave: Sustentabilidade; Gestão de Águas; Águas Cinzas.

\begin{abstract}
Sustainability has been increasingly discussed because it is a necessity. Adopting sustainable measures is one way we must protect the environment. There are many ways we can implement in our daily lives to mitigate the impacts generated, among them we can properly manage waste, reuse and recycle as much as possible, implement rainwater reuse systems and use solar energy. By adopting measures such as these in the economic, social and environmental spheres, we can say that we are exercising sustainability. In this context, the present work has as objective the elaboration of a roadmap for water management for popular houses, elaborating actions that lead to the reduction of water waste and better reuse of them. Therefore, a case study was carried out in a single-family residence of $216 \mathrm{~m}^{2}$,
\end{abstract}


showing the results of each stage. From the result, it can be concluded that gray water reuse and rainwater reuse systems are clear and real, contribute to water conservation, as they reduce the consumption of drinking water for less noble purposes and contribute to sustainability. water in cities.

Keywords: Sustainability; Water Management; Gray Waters.

\section{Resumen}

La sostenibilidad se ha discutido cada vez más porque es una necesidad. La adopción de medidas sostenibles es una de las formas en que debemos proteger el medio ambiente. Son muchas las formas que podemos implementar en nuestro día a día para mitigar los impactos generados, entre ellas podemos gestionar adecuadamente los residuos, reutilizar y reciclar en la medida de lo posible, implementar sistemas de reutilización de agua de lluvia y utilizar energía solar. Adoptando medidas como estas en los ámbitos económico, social y medioambiental, podemos decir que estamos ejerciendo la sostenibilidad. En este contexto, el presente trabajo tiene como objetivo desarrollar una hoja de ruta para la gestión del agua para las casas populares, desarrollando acciones que conduzcan a la reducción del desperdicio de agua y una mejor reutilización de las mismas. Por ello, se realizó un estudio de caso en una vivienda unifamiliar de $216 \mathrm{~m}^{2}$, mostrando los resultados de cada etapa. Del resultado se puede concluir que los sistemas de reúso de aguas grises y pluviales son claros y reales, contribuyen a la conservación del agua, pues reducen el consumo de agua potable para fines menos nobles y contribuyen a la sustentabilidad del agua en las ciudades.

Palabras clave: Sustentabilidad; Administración del Agua; Aguas Grises.

\section{Introdução}

Conforme a Declaração Universal dos Direitos da Água, publicada em 22 de março de 1992 pela Organização das Nações Unidas - ONU (1992), a água faz parte do patrimônio do planeta, sendo cada continente, cada nação, cada povo, cada região, cada cidade, cada cidadão responsável por este recurso. Ainda relata que, os recursos naturais de transformação da água potável são lentos, frágeis e muito limitados. Assim sendo a água deve ser manipulada com racionalidade, precaução e parcimônia (Ana, 2021).

Várias medidas de conservação de água têm sido adotadas visando diminuir o consumo de água, utilizando este recurso de maneira sustentável e racional, além de proteger os recursos hídricos da poluição, através da geração de menor volume de esgoto. Esse tema tem uma crescente importância na sociedade, visto que o aproveitamento desse recurso visa melhorias, como a diminuição do impacto ambiental e máxima integração com o ambiente.

Mesmo que a água seja um recurso renovável, o uso irresponsável compromete sua disponibilidade quantitativa e qualitativa. Sendo assim, o incentivo ao uso racional de água é uma forma de prevenir sua escassez. Gonçalves (2006), afirma que buscar fontes alternativas de água, tais como águas residuárias para reuso ou aproveitamento de águas pluviais é uma das formas de minimizar a utilização de recursos hídricos.

Para elaboração do roteiro de gestão da água para casas populares é preciso conhecer e adotar medidas que visam minimizar a consumo, utilizando-o de maneira sustentável e racional. Nos últimos anos a gestão desses recursos vem sendo um desafio para os governantes e até mesmo para a população que usa de forma exacerbada esses recursos de maneira irracional (Saraiva et al., 2009; Rocha et al., 2018).

Sendo assim, tendo em vista a crescente importância que a sustentabilidade tem adquirido nos últimos anos e a necessidade de que mais soluções sustentáveis sejam incorporadas no setor civil, o objetivo do trabalho é a elaboração de um roteiro para gestão das águas para casas populares elaborando ações que levem a diminuição do desperdício de águas e melhor reaproveitamento delas.

\section{Referencial Teórico}

\subsection{A escassez e a falta de água no Brasil}

O Brasil possui uma ampla diversificação climática em virtude de vários fatores como a configuração geográfica, a altitude, a extensão territorial - tanto em relação à latitude quanto à longitude -, o relevo e a dinâmica das massas de ar. Como 
corolário, o Brasil recebe uma abundante pluviometria que varia, sobre mais de $90 \%$ do seu território, entre 1.000 e mais de $3.000 \mathrm{~mm} / \mathrm{ano}$.

O país é dotado, também, de uma vasta e densa rede de drenagem que nunca seca sobre mais de $90 \%$ do território nacional, engendrando, certamente, a ideia de abundância de água no Brasil. Como corolário, sempre foi considerado um luxo, no Brasil, tratar esgotos antes de lançá-los nos rios. Umas das principais causas para a crise hídrica é o uso inadequado do solo. Com o avanço da fronteira agrícola, houve efeitos significativos pela ausência da vegetação nativa para proteger o solo, consequentemente impactando na quantidade e qualidade dos recursos hídricos (Rezende, Salgado \& Castro, 2018).

Segundo a coordenadora do programa Cerrado e Caatinga do Instituto Sociedade, População e Natureza (ISPN), Isabel Figueiredo, "a mudança do uso da terra tem alterado demais o ciclo da água e faz com que a gente tenha menos água nos rios, os rios muito assoreados e menor disponibilidade de chuva. Então, o ciclo da água está num pequeno colapso”.

Para evitar o agravamento da situação, é necessária uma evolução do ponto de visto ético e moral e não somente científico e tecnológico. "A mudança do clima é a maior falha de mercado da espécie humana, porque é algo em que a inteligência estratégica de sobrevivência do ser humano não funcionou e continua errando de forma insistente. E qual a consequência disso? É você ter o crescimento de conflitos que já estão estabelecidos, como disputa por água, energia e espaço, aumento de refugiados".

\subsection{Sustentabilidade nos Recursos Hídricos}

Ao longo das últimas décadas, a sociedade vem se conscientizando da importância do meio ambiente e sua preservação. As consequências do mal uso que fazemos dos recursos naturais tem sido catastrófica, secas e inundações de grandes proporções são consequências do aquecimento global e das mudanças climáticas e quase que por uma questão de sobrevivência; se faz necessário termos responsabilidade com o planeta em que vivemos (Barboza, Silva Alencar \& Alencar, 2020; Silva et al., 2020).

No que se refere o recurso água, verifica-se que $71 \%$ estão em forma de gelo nas calotas polares. Como o processo de transporte dessas geleiras é muito caro e não muito eficaz, quase não há atividades referentes ao abastecimento de localidades através do manuseio dessas calotas polares (icebergs). Os outros 29\% restantes de água potável no mundo estão distribuídos em águas subterrâneas (18\%), rios e lagos (7\%) e umidade do ar (4\%) (Fonseca et al., 2020).

Assim, percebemos que o problema da água para o ser humano reside no fato de a sua maior parte não estar viável para consumo. Apesar disso, mesmo com o fato de a proporção de água potável disponível ser reduzida, ainda sim estamos falando de uma quantidade muito grande de água. No entanto, o seu mau uso vem reduzindo drasticamente a sua disponibilidade, seja através da péssima manutenção dos rios, seja pela sua poluição. Por esse motivo, estima-se que a água seja um dos principais fatores geopolíticos ao longo do século XXI (Cantelle, Castro Lima \& Borges, 2018).

Outro fato agravante é a má distribuição dessa água potável pelo mundo. Algumas regiões do Oriente Médio e da África, por exemplo, apresentam uma significativa crise quanto ao abastecimento de água, o que se agrava com a ausência de saneamento básico para boa parte da população (Cantelle, Castro Lima \& Borges, 2018).

No caso do Brasil, há certo privilégio, pois é o país que possui a maior disponibilidade de água potável, com cerca de $11 \%$ do total. Porém, trata-se de uma falsa abundância, pois também em nosso território essa água é mal distribuída. A sua maior parte encontra-se na região Norte do país, zona menos habitada e com solos pouco agricultáveis. As regiões Sul, Sudeste, Centro-Oeste e Nordeste dividem a quantidade restante, sendo que essa última é a que mais sofre com os problemas de escassez de água (Pagnota \& Georges, 2020).

Por esse motivo, além de se promover uma maior conscientização popular sobre o correto uso, armazenamento e preservação da água e de suas fontes naturais, é preciso também a realização de políticas públicas para garantir o seu acesso 
por toda a população, com ações de democratização estrutural, como o saneamento básico. A sua disponibilidade define a estrutura e funções de um ambiente responsável pela sobrevivência de plantas e animais assim como todas as substâncias em circulação no meio celular que constituem o ser vivo (Bragato et al., 2018).

\subsection{O Tratamento das Águas Negras}

De acordo com Menezes et al. (2011), as águas negras são os efluentes provenientes das bacias sanitárias, incluindo principalmente fezes, urina e papel higiênico, podendo ou não conter água, e apresentam concentração mais elevada de microrganismos e matéria orgânica. Podem ser separadas em águas amarelas (urina) e águas marrons (fezes).

A divisão das águas negras e das águas de cinzas proporciona tratamento específico, o que torna a manutenção mais prática, eficiente, e possibilita a verificação da eficiência no tratamento que se utiliza. Há vários tipos de tratamentos de efluentes como químicos, físicos, e os biológicos que por sua vez são os mais viáveis e utilizados em residências rurais (Rebêlo, 2011). Como forma de tratamento de águas negras existe basicamente três tipos: banheiro seco, fossa séptica biodigestor e o tanque de evapotranspiração.

- Banheiro seco: é uma tecnologia de tratamento de efluentes sanitários, pelo processo de compostagem, que não utiliza o recurso "água", os resíduos são armazenados em coletores onde serão compostados; sendo uma das alternativas para o meio rural, e ou regiões com déficit de recursos hídricos.

- Fossa séptica biodigestor: é considerada um sistema inovador de esgoto sanitário composto por três caixas coletoras com 1.000 litros cada uma; elas são enterradas no solo, funcionam conectadas exclusivamente ao vaso sanitário e são interligadas entre si por tubos e conexões de PVC. A fossa biodigestora consiste em um tratamento biológico de águas negras por ação de digestão fermentativa. Isso é realizado através da biodigestão; que compreende como um processo que utiliza esterco bovino fresco ou de outro animal ruminante. No final deste processo, se obtém um adubo natural líquido; sendo utilizado na fertilização do solo (EMBRAPA, 2010).

- Tanque de evapotranspiração: é um tanque impermeabilizado construído com tijolos, o efluente é direcionado para dentro de uma câmara de recepção através de um cano de PVC, a câmara é feita com "tijolos baianos tijolos vasados" o efluente de dentro da câmara permeia as camadas de materiais cerâmicos e pedras, distribuídos ao redor dela, onde ocorre o início e a digestão anaeróbica das águas negras (Galbiati, 2009).

\section{Metodologia}

Realizou-se um caso em uma edificação existente ocorrendo nas seguintes fases distintas: caracterização da edificação e da demanda de água não potável; caracterização da oferta de fontes alternativas; avaliação dos custos envolvidos para a implantação do sistema de reuso de água.

Desterro é um município brasileiro do estado da Paraíba e integrante da Região Metropolitana de Patos. Localiza-se a uma latitude $07^{\circ} 17^{\prime} 26^{\prime \prime}$ sul e a uma longitude $37^{\circ} 05^{\prime} 38^{\prime \prime}$ oeste, encontra-se na Região Geográfica Imediata de Patos e na Região Geográfica Intermediária de Patos, na região da Serra do Teixeira, limita-se ao norte com o município de Cacimbas, ao leste com Livramento, a oeste com Teixeira e ao sul com o município de Itapetim, no estado de Pernambuco, estando a uma altitude de 591 metros. Sua população estimada em 2017 é de 8.306 habitantes. Possui uma área de 179 km², apresenta um clima semiárido com chuvas de verão.

O Município está incluído na área geográfica de abrangência do semiárido brasileiro, definida pelo Ministério da Integração Nacional em 2005. Esta delimitação tem como critérios o índice pluviométrico, o índice de aridez e o risco de seca. A divisão do estado da Paraíba em bioclimas classifica o clima de desterro como sub-desértico $2 b$, de tendência tropical com 9 
a 11 meses secos. A vegetação nativa é composta predominantemente de caatinga cariri e curimataú. A sudoeste ocorre também a mata serrana. As altitudes variam de $600 \mathrm{~m}$ a $753 \mathrm{~m}$ na Serra do Cariri.

\section{Resultados e Discussões}

\subsection{Gestão de águas na região}

O Estado da Paraíba é caracterizado por dois regimes de chuvas, um de fevereiro a maio, nas regiões do Alto Sertão, Sertão e Cariri/Curimataú; e o outro de abril a julho, no Agreste, Brejo e Litoral (Diniz et al., 2020). Mesmo durante esses dois regimes as chuvas são escassas fazendo com que a população sempre tenha dificuldades de obter água para consumo. Diante desses fatos, se faz necessário ter uma política de gestão de águas onde, gestão de recursos hídricos pode ser definida como o conjunto de ações destinadas a regular o uso, o controle e a proteção dos recursos hídricos, em conformidade com a legislação e normas pertinentes (Melo \& Lima, 2021).

Para o desenvolvimento de uma política de gestão de águas se faz necessário verificar o regime de chuvas da região e a sua periodicidade. Após a elaboração deste levantamento de dados, é possível elaborar estratégias para a gestão das águas. Como fonte de referência para o levantamento das informações pode-se consultar o Banco de Dados Agência Executiva de Gestão das Águas (AESA). Após organizar as estratégias adotadas, deve-se elaborar um plano do uso racional da água, no sentido de fazer uso eficiente da água e reverter este uso em benefícios durante o consumo. O plano deve contemplar: redução da quantidade de água extraída dos reservatórios; redução do consumo e desperdício de água; aumento da eficiência do uso de água; aumento da reciclagem e do reuso de água.

\subsection{Caracterização da Edificação}

O estudo de caso foi realizado em uma residência unifamiliar que fica em uma fazenda do município de Desterro, denominada de Fazenda Seu Aderbal. Fica localizada a 5,2 km de distância da cidade. A residência com aproximadamente $216 \mathrm{~m}^{2}$ fica localizada entre dois açudes que abastecem os reservatórios dela por meio de bombas (Figura 1). É composta por 4 quartos, 1 cozinha, 1 sala, dois banheiros e salão de para armazenar o milho e feijão na época da colheita. 
Figura 1: Localização da residência entre os dois açudes.

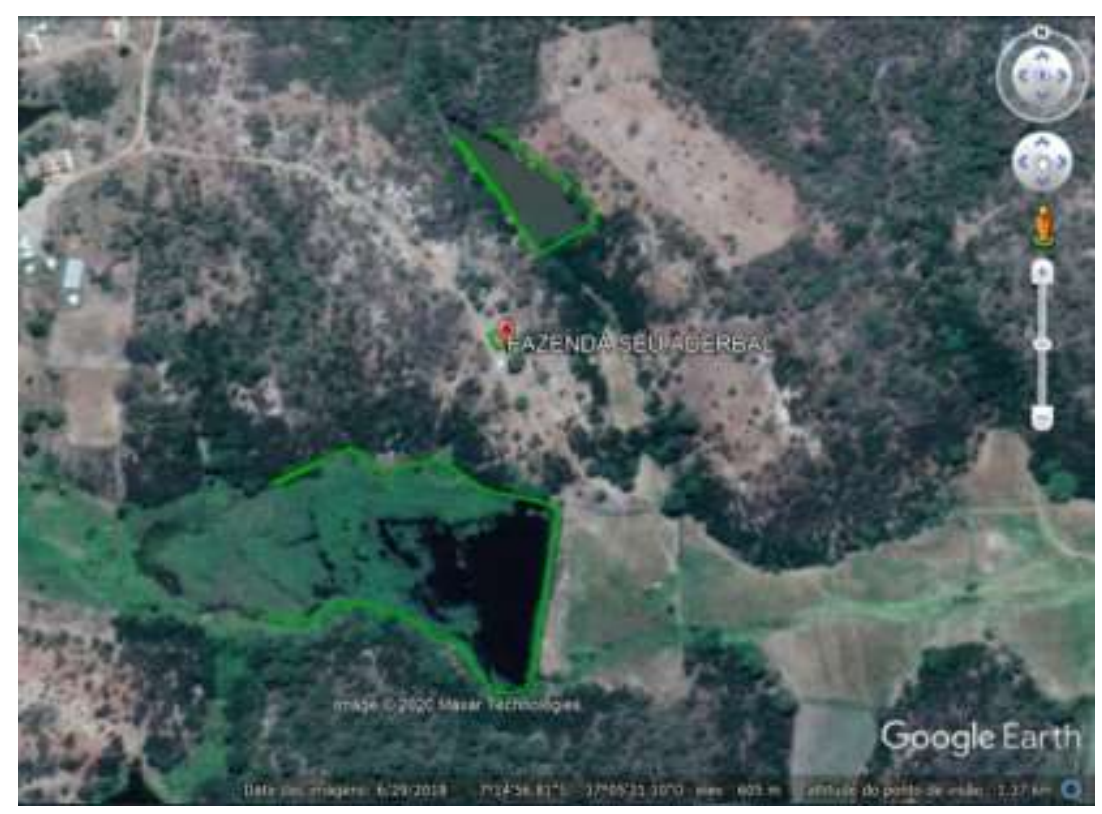

Fonte: Google Earth (2021).

\subsection{Desenvolvimento em Paralelo aos Projetos dos Moradores}

Foi implantado na residência um sistema de captação de água de chuva e um sistema para tratamento de reuso de águas cinza usando sistemas naturais. A implantação do sistema foi feita em comum acordo com os residentes, que tiveram plena consciência do desenvolvimento do projeto, colaboraram com informações de rotina necessárias para o estudo. Na região a chuva é pouca e mal distribuída, sendo comum encontrar nas casas da região do cariri, cisternas para armazenas água da chuva. O consumo diário varia muito de acordo com a oferta de água.

\subsubsection{Sistema de captação de água da chuva}

O sistema de captação de água da chuva foi implantando de acordo com o desenvolvido pelo SEBRAE, iniciando-se pelo cálculo da área do telhado disponível para captação, compra do material necessário como: filtros, bombas e cisternas, orientação técnica e mão de obra adequada para instalação.

A água da chuva captada escorre pelo telhado e a calha; no filtro são retidos as folhas, galhos e resíduos; é feita uma abertura para retirada das impurezas. Após o primeiro volume de chuva encher o reservatório, a água mais limpa vai para a cisterna que está devidamente tampada, longe de arvores, arbustos, fossas e deposito de lixo. 
Figura 2: Sistema de aproveitamento da água de chuva.

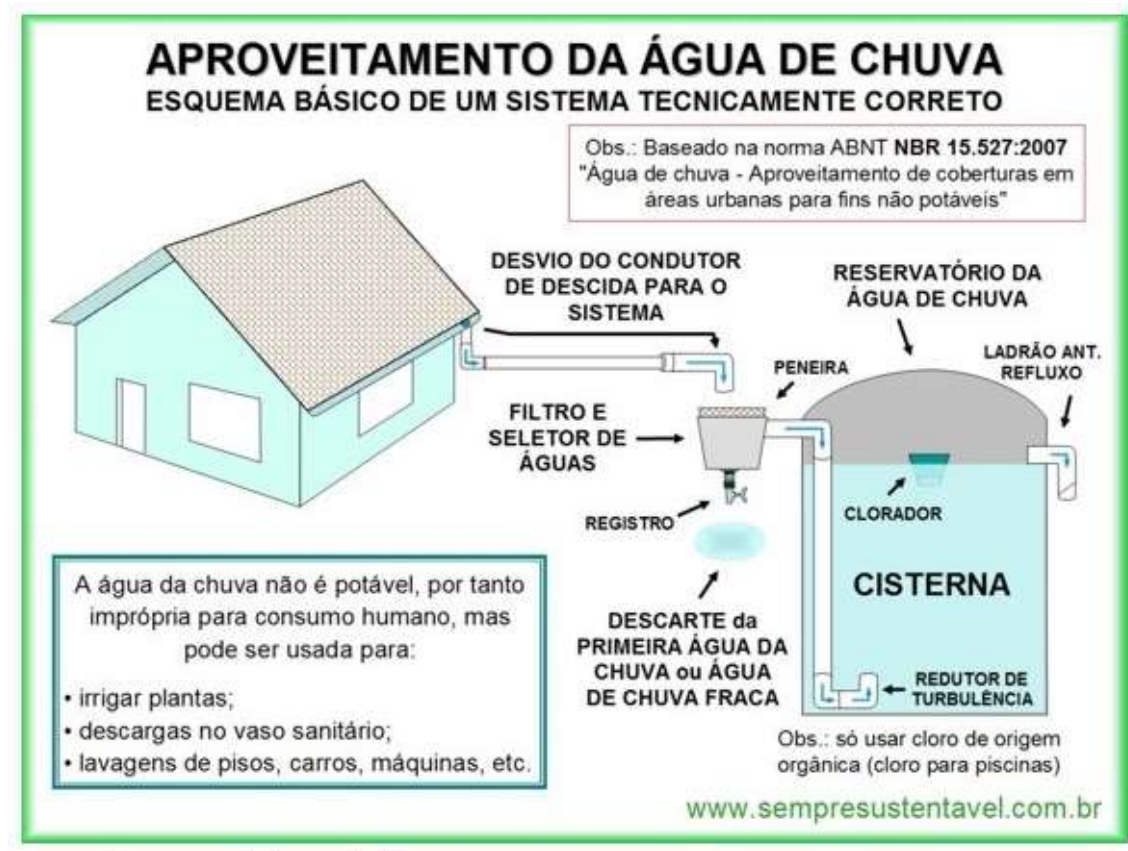

Fonte: Sempre Sustentável (2020).

Captar a água de chuva para o aproveitamento é uma forma de reduzir os custos, preserva e conserva um dos bens naturais mais escassos e ajuda a conter enchentes, pois retém parte da água que seria despejada na rede de esgoto. Além disso, o sistema pode ser instalado em ambientes rurais e urbanos.

\subsubsection{Sistema para tratamento de reuso de águas cinza}

O sistema de para tratamento de reuso de águas cinza foi elaborado de acordo com o sistema BIOágua (Projeto Dom Helder Câmara), conforme Figura 3, que reutiliza águas cinzas (água do banho, pias, tanques, máquinas de lavar etc.) para a agricultura familiar por meio do sistema de filtragem. As águas, antes lançadas diretamente nos quintais sem qualquer tratamento, contaminando o solo e os cursos d'água, agora são devidamente direcionadas para produção agroecológica, constituindo uma fonte rica de nutrientes. 
Figura 3: BIOágua Familiar

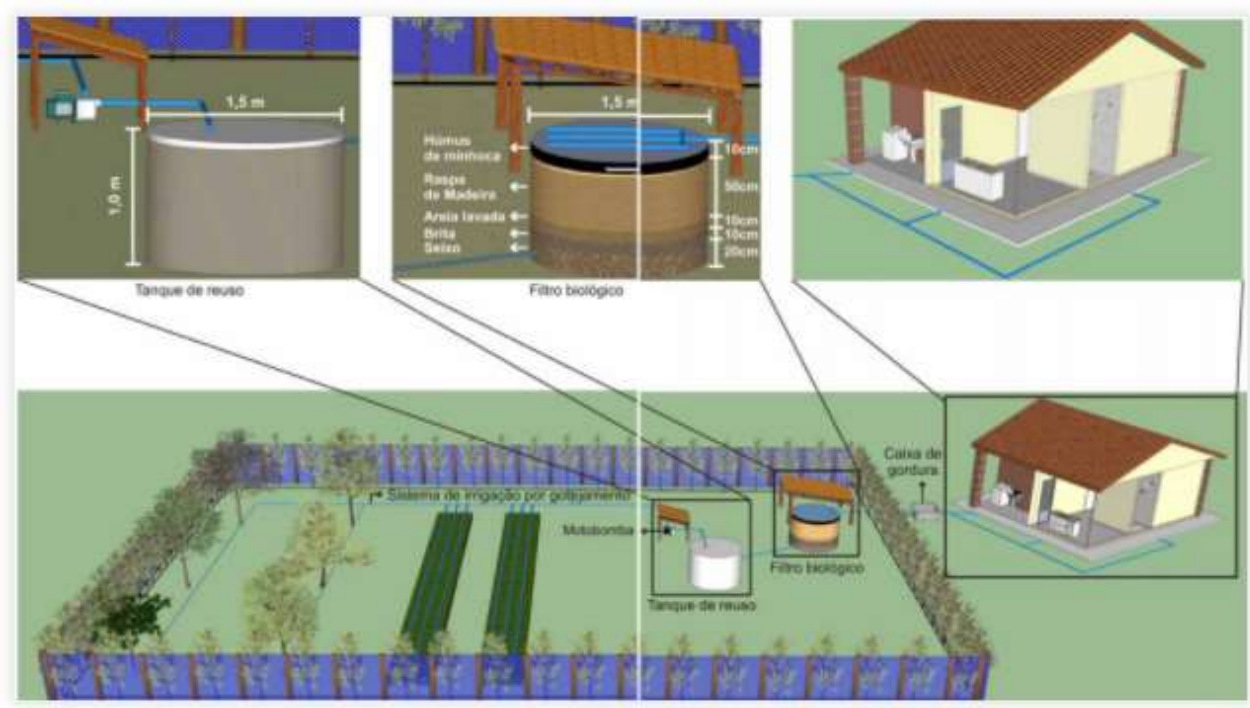

Fonte: SEBRAE (2020).

Esse sistema traz com sustentabilidade o uso dessa água consciente reaproveitando-a. A ideia é reaproveitar a água utilizada em casa. O sistema funciona da seguinte maneira: a água sai da residência por um único cano e segue por gravidade até o filtro construído ao lado num terreno mais baixo, após passar pelo filtro a água vai para um reservatório e de lá a água é bombeada para canteiros e hortaliças.

Na residência foram utilizados 2 filtros com 1,50m de diâmetro por 1,00m de profundidade. Para garantir uma boa filtragem a estrutura foi preenchida com várias camadas de diferentes materiais: $20 \mathrm{~cm}$ de seixos, $10 \mathrm{~cm}$ de brita, $10 \mathrm{~cm}$ de areia lavada, $50 \mathrm{~cm}$ de serragem, $10 \mathrm{~cm}$ de humus de minhoca. Nesse contexto, a Figura 4 apresenta o Sistema de Reuso de Águas de Cinza da Edificação analisada, no qual foi desenhado respeitando a topografia do terreno. 
Figura 4: Sistema de Reuso de Águas de Cinza

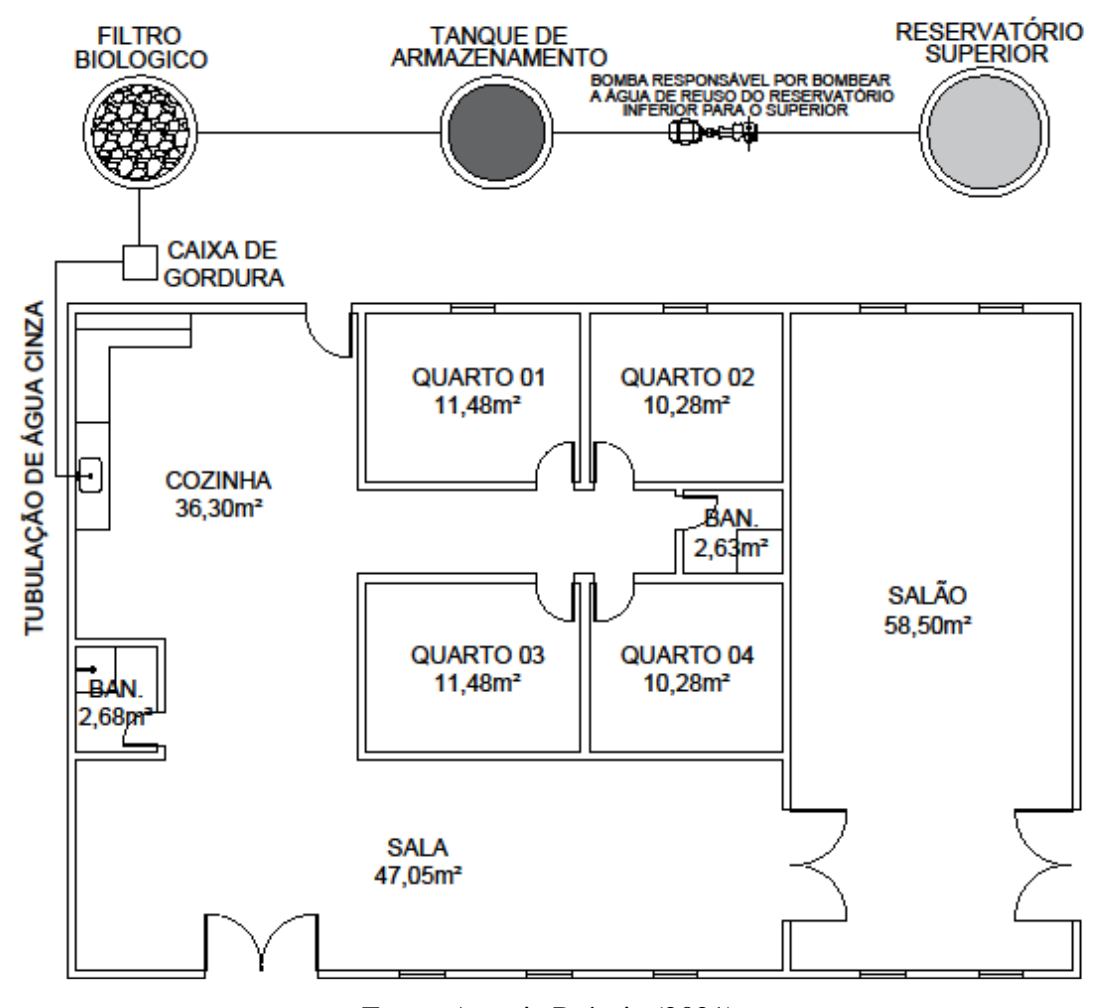

Fonte: Autoria Própria (2021).

Verifica-se pela Figura 4 o layout do projeto básico de Reuso de Águas de Cinza para casas populares. Nesse sistema, está presente a caixa de gordura provenientes das pias das cozinhas. Essa etapa de tratamento preliminar retém os residuais sólidos que juntos com a água da pia da cozinha, permitindo que somente a água siga pela tubulação para o esgoto para etapas posteriores do tratamento, retirando objetos maiores na água, bem como excesso de graxas e gorduras que possam prejudicar o tratamento da água residuária subsequente (Freitas, 2018).

Em etapas posteriores, há o tanque inferior (implantado para o armazenamento de água cinza advinha da etapa preliminar) e superior (etapa final do sistema). A água é deslocada de um reservatório para outro por meio de um sistema motor-bomba. Os reservatórios para reuso terão volumes conexos com o volume gerado na cozinha na edificação analisada.

Logo, como afirmam Roman et al. (2018), o reuso da água cinza é uma das formas mais sustentáveis no que se refere a preservação da água, visto que além de economizar os recursos hídricos, devolve-se menos poluição a jusante e, por conseguinte, menos deterioração ecológica. As diversas formas de tratamento para as águas cinzas, são eficazes no que diz respeito a remoção de microrganismos prejudiciais à saúde e ao bem-estar das pessoas, tornando-a melhor aceita para os fins a que se destina.

\section{Considerações Finais}

O presente trabalho objetivou elaborar um roteiro para gestão das águas para casas populares, elaborando ações que levem a diminuição do desperdício de águas e melhor reaproveitamento delas. Nesse sentido, o objetivo foi cumprido a partir do projeto básico de Reuso de Águas de Cinza para casas populares, a partir do Estudo de Caso na Zona Rural do município de Desterro, Paraíba.

Verificou-se que, apesar do Brasil apresentar grande disponibilidade de recursos hídricos, é possível ainda verificar grandes problemas de falta de água em muitas cidades brasileiras. A conscientização da população sobre a importância da 
economia e conservação de água requer uma mudança cultural ampla. Sendo assim, percebeu-se grande importância de sistemas de reuso de água cinza e aproveitamento de água de chuvas, visto que contribuem para a conservação da água, pois diminuem o consumo de água potável para fins menos nobres e contribuem para a sustentabilidade hídrica das cidades, minimizando também, os níveis de poluição dos corpos hídricos. Portanto faz-se necessário o estabelecimento de normas que conduzam ao aproveitamento seguro dessas fontes de água.

Nesse contexto, o presente estudo permitiu abordar os conceitos gerais sobre reuso de águas cinzas, tratamento de águas residuárias e apresentar os métodos utilizados na elaboração e na implantação dos sistemas, bem como apresentar os produtos e tecnologias economizadoras oferecidas pelo mercado de forma acessível, o que os torna cada vez mais palpável para os padrões de construção atual.

No projeto final, foi apresentado o layout, no qual consta a caixa de gordura, no qual tem como finalidade reter os residuais sólidos que juntos com a água da pia da cozinha, permitindo que somente a água siga pela tubulação para o esgoto para etapas posteriores do tratamento. Posterior a essa etapa, há o tanque inferior e superior, em que a água é deslocada de um reservatório para outro por meio de um sistema motor-bomba. O sistema funcionará da seguinte maneira: a água sairá da residência por uma única tubulação e seguirá por gravidade até o filtro construído ao lado em um terreno mais baixo, após passar pelo filtro a água vai para um reservatório e de lá a água é bombeada para canteiros e hortaliças.

\section{Referências}

AESA. (2021). Precipitação máxima dos municípios/postos no ano 2021. http://www.aesa.pb.gov.br/aesa-website/meteorologia-chuvas/?formdate=2021-09$06 \&$ produto $=$ municipio $\&$ periodo $=$ anual

ANA. (2021). Dia Mundial da Água. https://www.gov.br/ana/pt-br/acesso-a-informacao/acoes-e-programas/dia-mundial-da-agua

Associação Brasileira de Normas Técnicas - ABNT NBR 10.281. (2003). Torneira de pressão - requisitos e métodos de ensaio. Rio de Janeiro.

Barboza, E. N., da Silva Alencar, G. S., de Alencar, F. H. H., \& de Moraes Felipe, Á. G. (2020). Influência da arborização nas variáveis climáticas em ruas com e sem asfaltamento na cidade de Barbalha-CE. Brazilian Journal of Development, 6(1), 980-986.

BIOÁGUA FAMILIAR. (2012). Reuso de água cinza para produção de alimentos no Semiárido. Projeto Dom Helder Câmara. Recife 2012. Disponível em: https://www.sebrae.com.br/Sebrae/Portal\%20Sebrae/UFs/RN/Anexos/Semiarido-Reuso-de-aguas-cinzas.pdf. Acesso em: 07 de set. 2021.

Bragato, M., Ponzilacqua, B., Peter, C. M., Picoli, T., \& Zani, J. L. (2018). A água e a saúde no meio rural. Educação ambiental nas escolas. Expressa Extensão, 23(1), 74-82.

Cantelle, T. D., de Castro Lima, E., \& Borges, L. A. C. (2018). Panorama dos recursos hídricos no mundo e no Brasil. Revista em Agronegócio e Meio Ambiente, 11(4), 1259-1282.

Diniz, R. R. S., Alencar, M. L. S., Medeiros, S. A., Guerra, H. O. C., \& Sales, J. C. R. (2020). Índice de anomalia de chuvas da Microrregião do Cariri Ocidental Paraibano. Revista Brasileira de Geografia Física, 13(06), 2628-2640.

Fonseca, P. F., da Silva, J. R., \& da Silva Fonseca, E. (2020). Análise da viabilidade da separação de água de chuveiros e pias para reúso. Research, Society and Development, 9(2), e14921938-e14921938.

Freitas, A. L. S. de. (2018). Reuso de água cinza residencial e proposta de tratamento. 2018. 36 f. Trabalho de Conclusão de Curso - Universidade Federal do Rio Grande do Norte.

Galbiati, A. F. (2009). Tratamento domiciliar de águas negras através de tanque de evapotranspiração. 2009.38 p. Dissertação - Universidade Federal de Mato Grosso do Sul.

Gonçalves, R. (2016). Uso Racional da Água nas Edificações. Rio de Janeiro: ABES, 2006. Programa de pesquisa em saneamento básico. p. 73-152.

Melo, V. D. S., \& Lima, L. M. (2021). Caracterização da Chuva da Microrregião de Catolé do Rocha no Estado da Paraíba Baseada em Estatística Aplicada. Revista Brasileira de Meteorologia, 36, 97-106.

Menezes, C. dos S. et al. (2011). Quantificação de águas residuárias para reuso na perspectiva do saneamento ecológico. In: Simpósio Brasileiro de Recursos Hídricos, v. 19, n.1.

Ministério de Meio Ambiente. (2005). Construção Sustentável. https://www.mma.gov.br/comunicacao/campanhas/item/8059

Pagnota, G. H., \& Georges, M. R. R. (2020). Recursos hídricos no Brasil: um estudo bibliométrico de como o assunto está sendo tratado no mundo científico. Periódico Eletrônico Fórum Ambiental da Alta Paulista, 16(6). 
Research, Society and Development, v. 11, n. 2, e34811225442, 2021

(CC BY 4.0) | ISSN 2525-3409 | DOI: http://dx.doi.org/10.33448/rsd-v11i2.25442

Rebêlo, M. M. P. S. (2019). Caracterização de águas cinzas e negras de origem residencial e análise da eficiência de reator anaeróbio com chicanas. 2019. 113 p. Dissertação de Mestrado em Recursos Hídricos e Saneamento - Centro de Tecnologia, Programa de Pós-Graduação em Recursos Hídricos e Saneamento.

Rezende, É. A., Salgado, A. A. R., \& Castro, P. D. T. A. (2018). Evolução da rede de drenagem e evidências de antigas conexões entre as bacias dos rios Grande e São Francisco no sudeste brasileiro. Revista Brasileira de Geomorfologia, 19(3).

Rocha, C. M., da Silva Bassanelli, F., dos Santos Fernandes, L., \& de Oliveira Espíndola, L. C. (2018). Crise Hídrica: Estratégias utilizadas em indústrias no Vale do Paraíba como forma de economia na utilização da água. Revista Científica on-line-Tecnologia, Gestão e Humanismo, 8(1)

Roman, D. et al. (2018). A importância do reuso de águas cinzas para fins residenciais. In: Encontro Mineiro de Engenharia de Produção - EMEPRO, v. 9, n.1.

Saraiva, C. B., Mendonça, R. C. S., de Lima Santos, A., \& Pereira, D. A. (2009). Consumo de água e geração de efluentes em uma indústria de laticínios. Revista do Instituto de Laticínios Cândido Tostes, 64(367), 10-18.

SEBRAE. (2020). Captação de Água da Chuva.

http://sustentabilidade.sebrae.com.br/sites/Sustentabilidade/Para\%E2\%80\%93sua\%E2\%80\%93Empresa/Publicacoes/Infograficos/Capta\%C3\%A7\%C3\%A3ode-\%C3\%A1gua-da-chuva

Silva, E. M., Barboza, E. N., de Morais, J. M. P., de Souza, J. H. A., \& de Oliveira, B. B. (2020). Análise de sensação térmica no município de Barbalha, Ceará. Research, Society and Development, 9(7), e98973795-e98973795. 